\title{
Representaciones cartográficas e iconográficas de Mendoza en tiempos coloniales: la ciudad y el Canal-Zanjónı
}

\section{Cartographic and iconographical representations of Mendoza in colonial times: the city and the Canal-Zanjón.}

\author{
Jorge Ricardo Ponte* \\ Instituto de Ciencias Humanas, Sociales y Ambientales - Consejo Nacional de Investigaciones \\ Científicas y Técnicas, Mendoza \\ jorgericardoponte@gmail.com
}

1. Una versión preliminar de este artículo fue publicada en las Actas de las 1as. Jornadas de Investigación "Ríos urbanos: nuevas perspectivas para el estudio, diseño y gestión de los territorios fluviales". Facultad de Arquitectura y Urbanismo, Universidad Nacional de La Plata / Instituto de Arquitectura y Urbanismo, Universidad Nacional de San Martín, 2 y 3/11/ 2017. ISSN-e 2618-1975.

* Es Arquitecto e Investigador Científico del CONICET / Doctor en Sociología de l'École des Hautes Études en Sciences Sociales de París. 1998. / Postgraduado en el Instituto de Restauro de Monumentos e Historia de la Arquitectura de la Università degli Studi di Firenze Florencia, Italia en 1978. / Diplomado en Historia Latinoamericana en la Universidad de la Sorbonne Nouvelle, París III, Francia, en 1995. / En 2010 obtiene la prestigiosa BECA de la John Simon GUGGENHEIM Memorial Foundation (NYC, USA) para América Latina y el Caribe (categoría: Humanidades; campo de estudio: Arquitectura, Planificación y Diseño). 


\section{Resumen:}

El relato sobre la evolución de las ciudades americanas, de manera excepcional explica cómo se pasa, de la foto inicial que constituye el plano fundacional, al primer plano real que aparece sobre dicha ciudad, a veces siglos después. Es decir, por qué este primer plano real tiene tan poco que ver con aquel ideal inicial. Qué elementos contribuyeron a los cambios que se advierten en la dirección de las calles, en la distribución de los solares o parcelas, en el alejamiento o acercamiento a costas de mares o ríos, etc.

Uno de estos modificadores importantes tiene que ver siempre con la necesidad imperiosa de aprovisionamiento de agua potable y del agua de para riego de chacras y quintas de esa novel ciudad.

Mendoza no fue la excepción a la ausencia de un relato explicativo que diera cuentas de estos cambios y modificaciones hasta que nosotros (a partir de 1987) cambiamos el paradigma explicativo de los cambios en la topografía y sus consecuencias en el espacio.

Palabras clave: Planos; Agua; Acequias; Mendoza

\section{Abstract:}

The story of the evolution of American cities, exceptionally explains how it passes, from the initial photo that constitutes the foundational plan, to the first real plan that appears on said city, sometimes centuries later. Why this first real plan has so little to do with that initial idea. What elements contributed to the changes that are noticed in the direction of the streets, in the distribution of the lots or plots, in the distance or the approach to coasts, seas or rivers, etc.

One of these important modifiers has to do with the imperative need of supplying drinking water and water for the irrigation of farms for that new city.

Mendoza was no exception to the absence of an explanatory description that would account for these changes and modifications until we (as of 1987) modified the explanatory paradigm of changes in topography and its consequences in the area.

Keywords: Plans; Water ; Ditches; Mendoza 


\section{Introducción}

En la historiografía tradicional, en trabajos que aluden al espacio, a la ciudad, o al territorio, las referencias espaciales, son simplemente enunciadas como texto, a veces correlacionadas con otras, pero siempre de una manera literaria, jamás gráfica.

La documentación gráfica, tal como pueden ser planos históricos y mapas, cuando aparecen, se los utiliza con la idea de ilustración, tanto como podría hacerse con una fotografía o un grabado antiguo. Se los usa para amenizar la lectura de tantas páginas de puro texto. Así entendido, el espacio, al cual se alude en el relato, nunca aparece identificado en términos espaciales o en relación grafica con el territorio que lo contiene. La crónica, aún la de temática espacial, en esta manera de relatar la historia del territorio, nunca traspasa la forma narrativa.
Se desperdicia así la posibilidad de considerar también a estos documentos de carácter primario como una fuente privilegiada de información histórica. Es cierto que, para la utilización de la evidente y provechosa información que pueden, potencialmente, proporcionar los planos históricos, conspira la mala calidad de sus reproducciones fotográficas [ver figura $N^{0} 1$ ], o la utilización de fotocopias (en vez de originales) lo que rebaja sus atributos y, por ende, su legibilidad.

No siempre los estudiosos advierten esta necesidad de vincular el hecho histórico, o una secuencia de hechos históricos, con su localización en el espacio, como una falencia o una debilidad. Lo cual no facilita el seguimiento espacial de un determinado proceso histórico.

El espacio siempre es, por cierto, el escenario inevitable donde se desarrolla la otra historia más

Figura No 1. Plano de distribución de solares, chacras y ejido de Mendoza de 1561. Levantado por el fundador Cap. Pedro del Castillo.

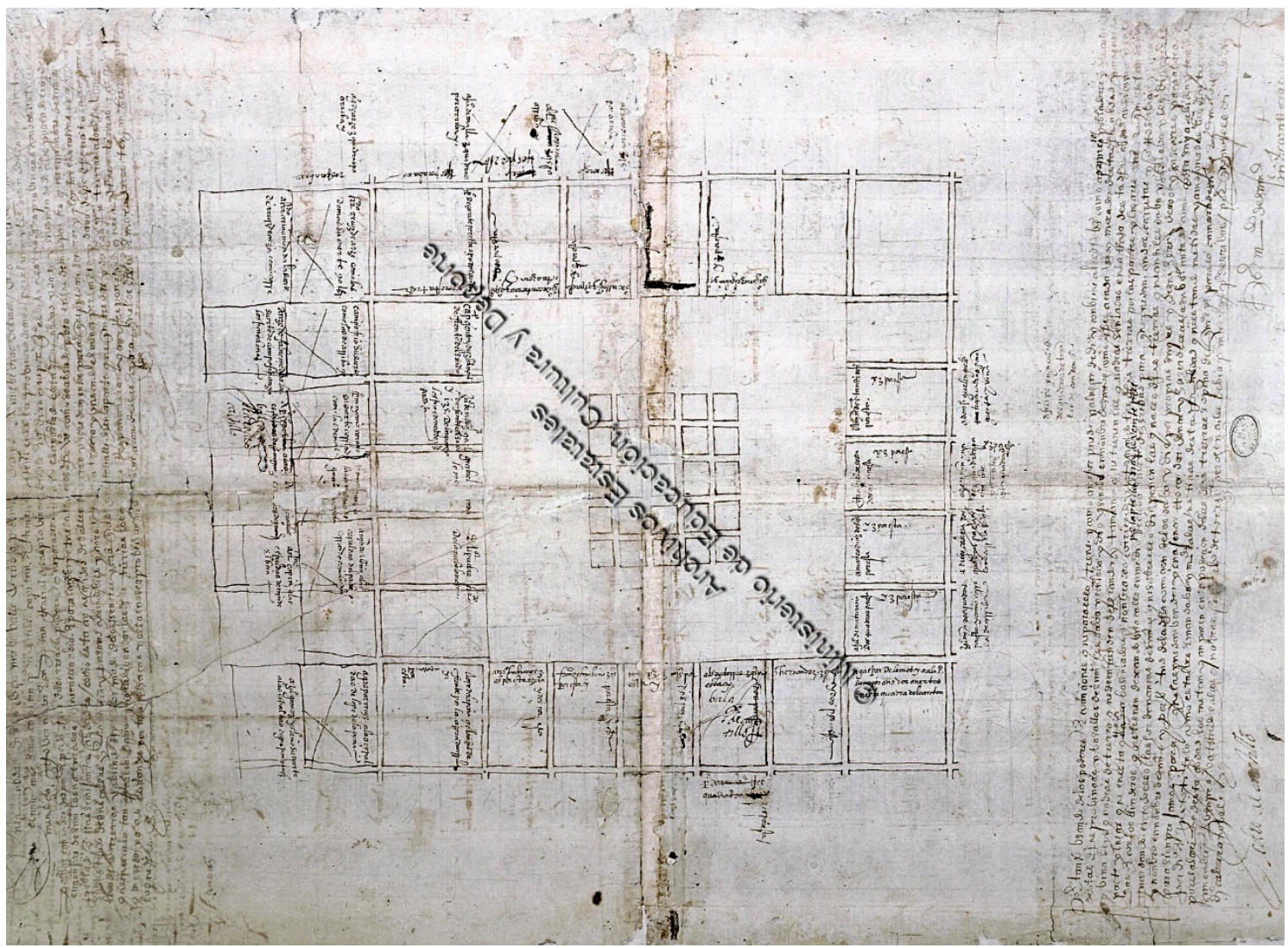

Fuente: Archivo General de Indias. Extraído de la página web del AGI. 
tradicional. En contraste, nuestra línea de investigación, desde hace muchos años y sobre la que se asienta nuestro mayor trabajo y producción, es aquella de vincular los procesos histórico-culturales con los espaciales: incorporando espacio a la historia e historia al espacio. Es decir, relacionando los desarrollos históricos, políticos, sociales, económicos, etc., con lo espacial, de manera de poder explicarnos el presente.

\section{El origen del Zanjón según la representación social contemporánea}

En 1933, el Ingeniero hidráulico Jacinto Anzorena elevó al entonces Ministro de Obras Públicas de la Provincia, un detallado relevamiento del Zanjón (actual Cacique Guaymallén) acompañarlo por algunas consideraciones importantes que nos parece útil rescatar.

El Informe recurre a Abraham Lemos (PROVINCIA DE MENDOZA, 1910)para brindar la versión tradicional sobre el origen de este curso de agua. Según la misma, los naturales habrían referido al fundador Pedro del Castillo, que hacía más de un siglo, unos ingenieros incaicos enviados por Yupanqui, el $8^{\circ}$ emperador inca, habrían arribado y construido los canales de riego que se tenían a la vista. Cada canal habría pertenecido a una agrupación de familias, las que se dedicaban a la agricultura (sembrando maíz y papa) y se identificaban por los nombres de los jefes de la tribu. Así, el principal pertenecía a Allayme, el inferior al cacique Tovar [sic] y el intermedio sería el que hoy se conoce como Zanjón Guaymallén. (ANZORENA, 15/9/1933, pág. folio1)

Respecto de esta versión, opina Anzorena:

"Esta leyenda cuyo origen no conocemos ha motivado la creencia generalizada, y en nuestro concepto errónea, de que el cauce actual del Zanjón fue desde su origen un cauce artificial. Tomando la leyenda como verídica, debemos interpretarla conformándola con los hechos históricos y en los accidentes naturales de orden geológico.

\begin{abstract}
Es evidente que los primitivos pobladores de la zona que hoy ocupa Mendoza estaban agrupados en tribus nómades que vivían de la caza, ya que fueron los ingenieros de Yupanqui quienes los iniciaron en el cultivo de la tierra; estas tribus nómades debieron establecer sus campamentos en las proximidades del agua, elemento indispensable para la vida, $y$ allí los encontraron los emisarios del Inca. El agua que en tanta abundancia existía como para utilizarla en el riego de las tierras, no podía proceder sino de un brazo del Río, que más tarde tomó el nombre de Zanjón, puesto que no se conocen, ni la tradición nos dice que se hayan conocido otras fuentes que pudieran haberse utilizado a tal objeto.

Por otra parte, la enormidad de la obra, la indolencia de los indígenas, la falta de elementos y el recorrido tortuoso del cauce sobre un terreno relativamente plano $y$ de pendiente uniforme, constituyen otras tantas razones que justifican nuestra convicción de que el Zanjón no ha sido sino un brazo del Río Mendoza." (ANZORENA, 15/9/1933, pág. folio 2)
\end{abstract}

\section{La ciudad fundacional}

La "ciudad de Mendoza, Nuevo Valle de Rioja" fue fundada en 1561 a la vera de un canal-acequia de origen indígena conocida, en tiempos pre hispánicos, como "Acequia Alta de Tantaiquén".Esto no lo reconoció el fundador (PONTE, 2008, pág. 29), ni en su plano fundacional que fue deliberadamente esquemático, ni tampoco en otro plano complementario de repartimientos de tierras [ver figura $N^{0} 1$ ] sino lo dirá la documentación cartográfica hídrica posterior.

Un ejemplo muy elocuente de la diferencia de nuestro enfoque y apreciación lo constituye el contrastar el plano de distribución de chacras y 
Figura 2.Repartimiento de tierras y Ejido de la Ciudad a los vecinos de Mendoza. Infografía propia construida en base al plano ideal del fundador Pedro del Castillo en 1561 [ver Figura № 1] y a información hídrica documental posterior.

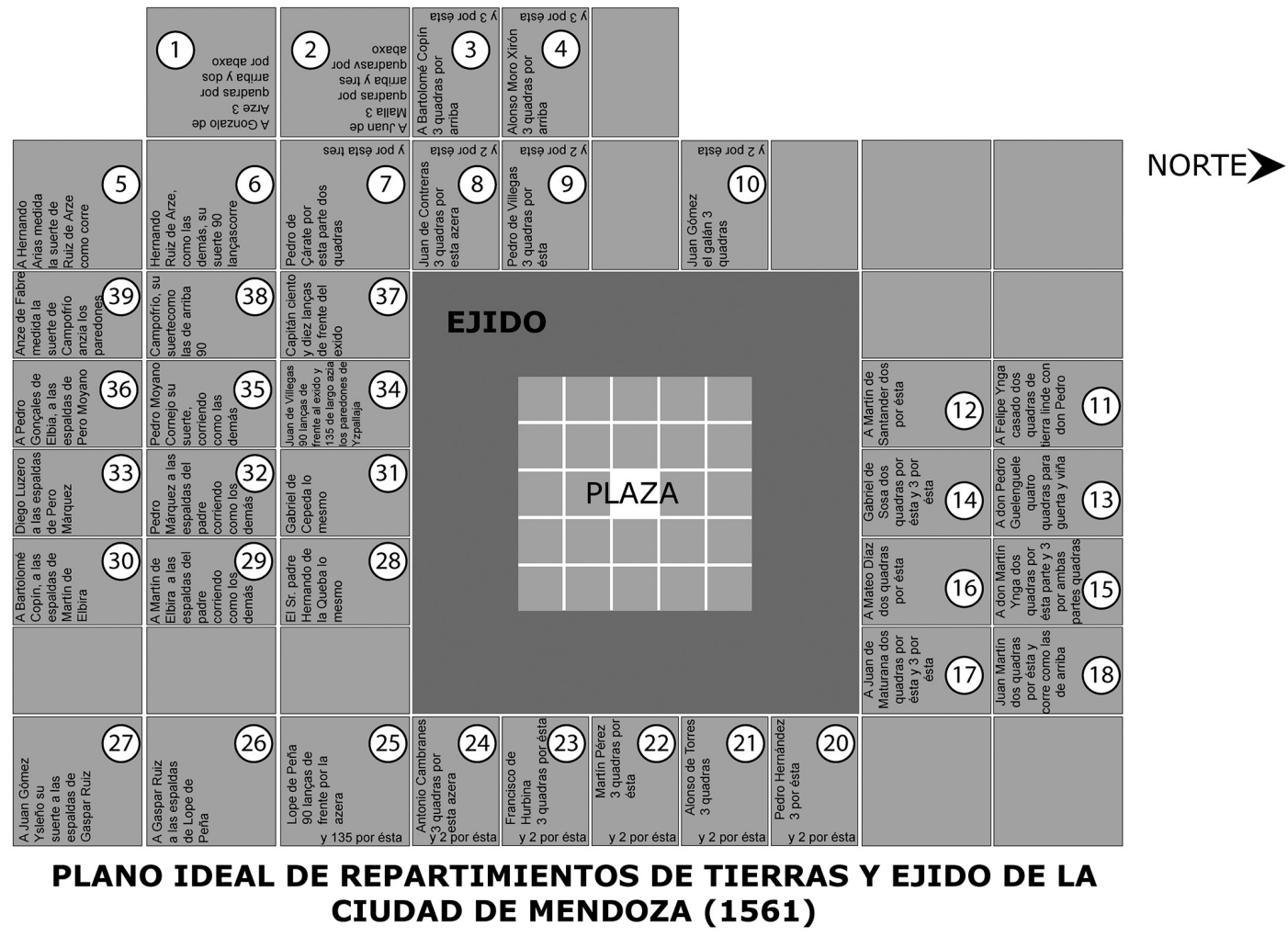

Fuente: Infografía de elaboración propia a partir de información documental

ejido de la ciudad levantado por el fundador de la Ciudad en 1561 y nuestra infografía condensada en la figura 1. En efecto, basta ver el plano de repartimiento original (1561) con nuestra infografía (figura 1).

La "Acequia Alta de Tantaiquén" [ver Figura 3] corría paralela a la actual calle Alberdi de San José y a una distancia de unos 50 metros, aproximadamente, por donde el terreno hace una cresta o una loma. Su posición, más elevada, permitía que dicha acequia pudiera regar a ambas márgenes, derecha e izquierda; hacia el este y hacia el oeste. (ver Figura 3) Sobre la margen izquierda de este canal, se estableció en 1561 una cuadrícula de 5 por 5 manzanas, con una plaza central, la que en los primeros años se desplazó hacia el este acercándose más hacia "Acequia Alta de Tantaiquén".

A esta acequia se la renominó primero como "la acequia que pasa por este Pucará'[ver Figura 3]en los primeros doscientos años de vida de Mendoza, y luego con el nombre de "Acequia de la Ciudad" antes que se produjera la aparición del "zanjón" cacique Guaymallén, a mediados del siglo XVIII. Hacia fines del siglo XVIII, la veremos en los documentos coloniales con el nombre de acequia Tovar.Esta "Acequia de la Ciudad" aunque no pasaba por el centro de la ciudad colonial, sino por un costado; recibe este nombre por ser la continuidad de la Acequia Grande de la ciudad (actual Canal Zanjón) en el trayecto que coincidía con el casco urbano de la ciudad colonial.

El pucará indígena [inca] [ver Figura 3]que estaría ubicado en el extremo norte del Canal Zanjón, justo antes de doblar hacia el este y de cuyas trazas dan cuenta los planos de 1822, 1846, $1867 / 74,1872 \ldots$

A pesar que en el Acta de los Caciques Comarcanos de 1574 (PONTE, 2006, pág. 43) se habla 


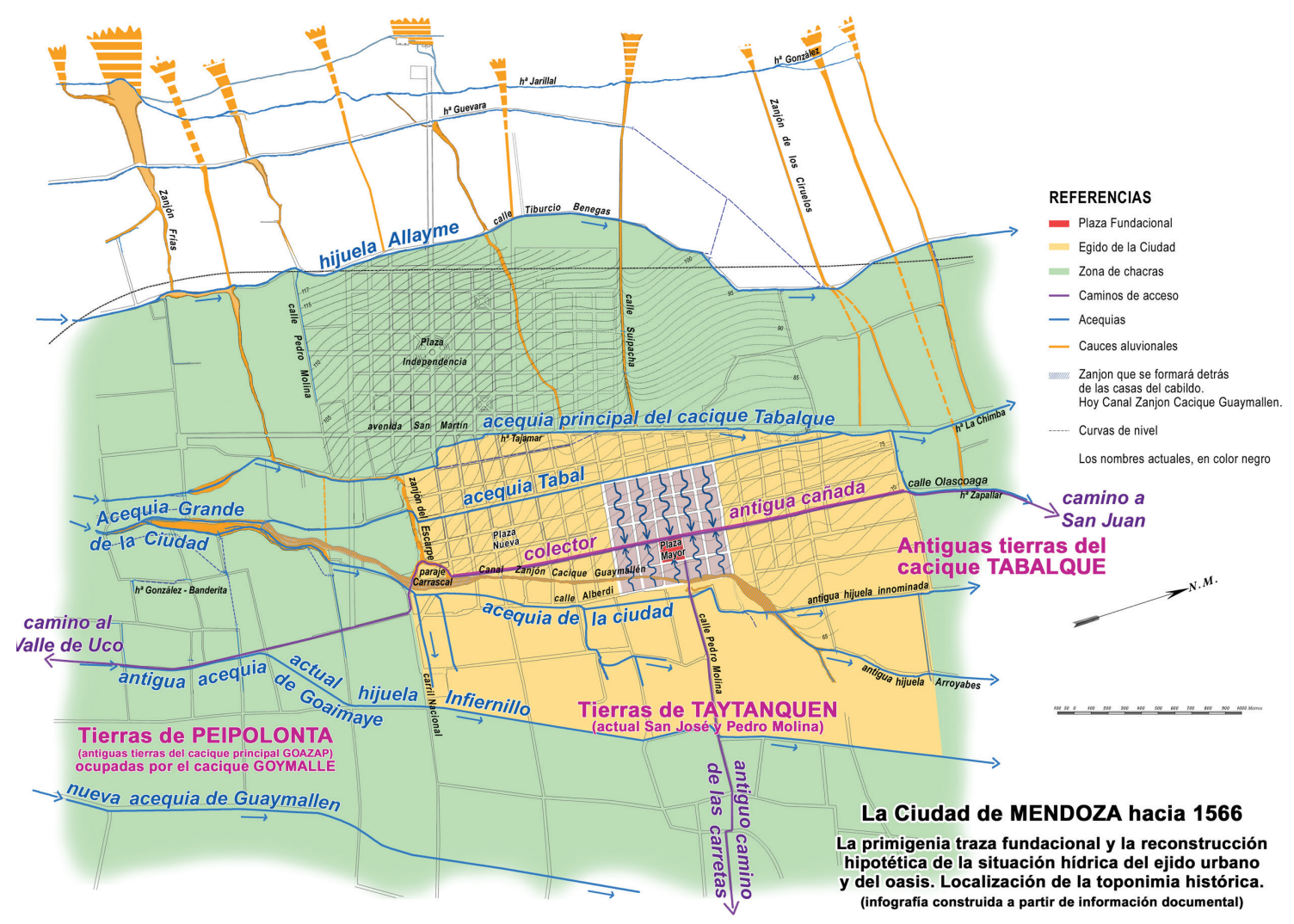

Fuente: PONTE, 2006, pág. 53

de la "acequia alta de Tantayquen" como un referente del territorio indígena pre hispánico, nunca más se vuelve a oír hablar de esta acequia. A nuestro entender porque en el acta de 1566 esa sería, precisamente, "la acequia que pasa por este pucará".Existe, precisamente, un Acta Capitular de Mendoza del 20 de noviembre de 1574 que confirma la existencia de esta acequia antigua. El documento refiere concretamente a una chácara "de pan llevar" [para plantar trigo]en la ciudad y respecto de la cual el Cabildo hizo merced a Andrés Páez. La misma lindaría con la chácara de Diego de Cabrera en treinta cuadras de cabezada y el largo que tuviere ésta.

Por otro lado, el $1^{0}$ sistema de riego de la ciudad fundacional fue, según nuestras investigaciones, fue la "acequia alta de Tantayquen" o "Acequia de la Ciudad" hacia el oeste, en una longitud de dos cuadras, hasta el colector co- nocido como "la calle de la Cañada". La plaza fundacional se regaba con esta acequia y de allí, probablemente, su nombre de "Acequia de la Ciudad".[ver Figura 4].

Estamos hablando de las tierras próximas a la actual plaza Pedro del Castillo] hacia el este de la ciudad fundacional, era la antigua acequia alta de Tantayquen "que está junto a los paredones del Inga que llaman Pucará" [los que estaban a lo largo de la actual calle Alberdi]. Es decir, la chácara en cuestión se ubicaba por el este entre la acequia de Guaimaien y por el oeste con la del pucara, es decir totalmente en la actual zona de San José del Departamento de Guaymallén.

Según creemos entender, cuando en el siglo XIX se institucionalizó el curso del Zanjón ya no se habla en los planos de la "Acequia de la Ciudad", sino simplemente del "Zanjón" que riega 


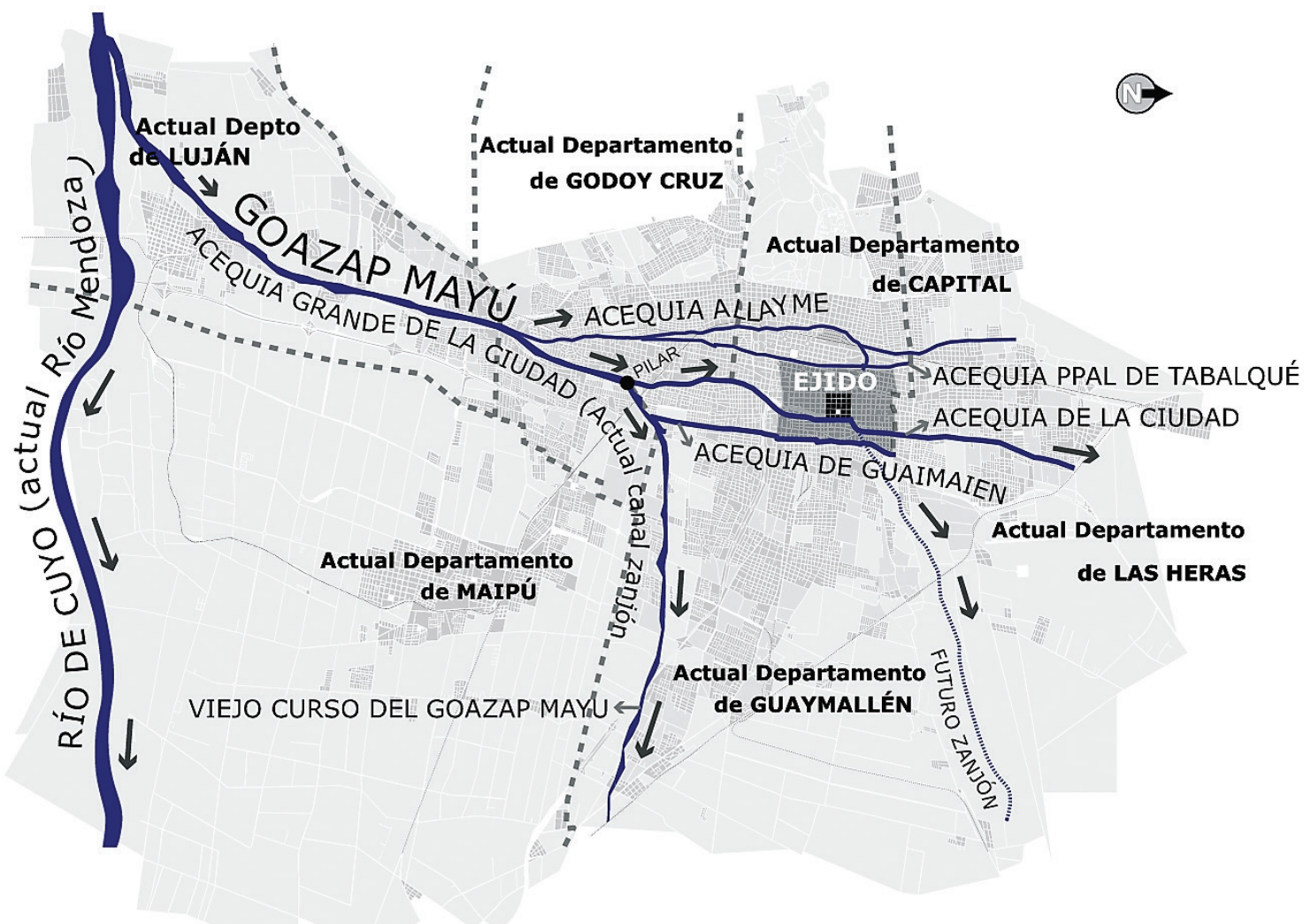

\section{El actual Área Metropolitana de MENDOZA hacia 1561/66}

Fuente: Infografía de elaboración propia a partir de información documental

a la ciudad. Es, entonces, cuando vemos aparecer a la otrora "Acequia de la Ciudad" como "acequia de Tovar" por pasar, precisamente por las tierras de los Tovares, tierras sobre el actual carril Nacional y Alberdi, margen sur, que originariamente habían sido de propiedad de Francisco de Urbina y que sus descendientes vendieron a Marcos Tovar y que regaba las actuales zonas de San José y Pedro Molina.

Al cruce de la "Acequia de la Ciudad"y luego al cruce del Zanjón [actual Canal Zanjón] por este lugar se lo conoció como la puerta y el paso de Tovar y era el ingreso a la ciudad por el camino nuevo del Litoral [actual carril Nacional]. (ver Figura 5)

A esta acequia "huarpe" la conoceremos [posterior $\neg$ mente, en el siglo XIX] como acequia Tovar (en sus dos brazos: el Tovar chico y el Tovar grande)(ver Figura 5)ambas con toma de agua en el actual Canal Zanjón, estaba ubicada, hacia el este y no al oeste del canal-zanjón y de la propia Ciudad. La acequia Tovar no ha perdurado hasta el presente. Fue cegada hacia los años '70 del siglo XX. Otro ramal con el mismo nombre nace más hacia el norte del curso antiguo en una toma sobre el Canal Zanjón, a la altura del distrito del Bermejo.

En algunos otros planos del siglo XIX aparece dibujado (parcial o totalmente) el curso de esta acequia y hay pequeñas variaciones en el mismo de un plano a otro y parecen desprenderse de su curso, canales secundarios o hijuelas, a cuya orilla aparecen dibujados caseríos que persisten de un plano a otro. Respecto de la ubicación del equipamiento molinero, varía según el plano pero, sin dudas, es uno de los canales activadores de molinos por excelencia. 
Figura 5. Infografía de elaboración propia a partir de información documental [1858].

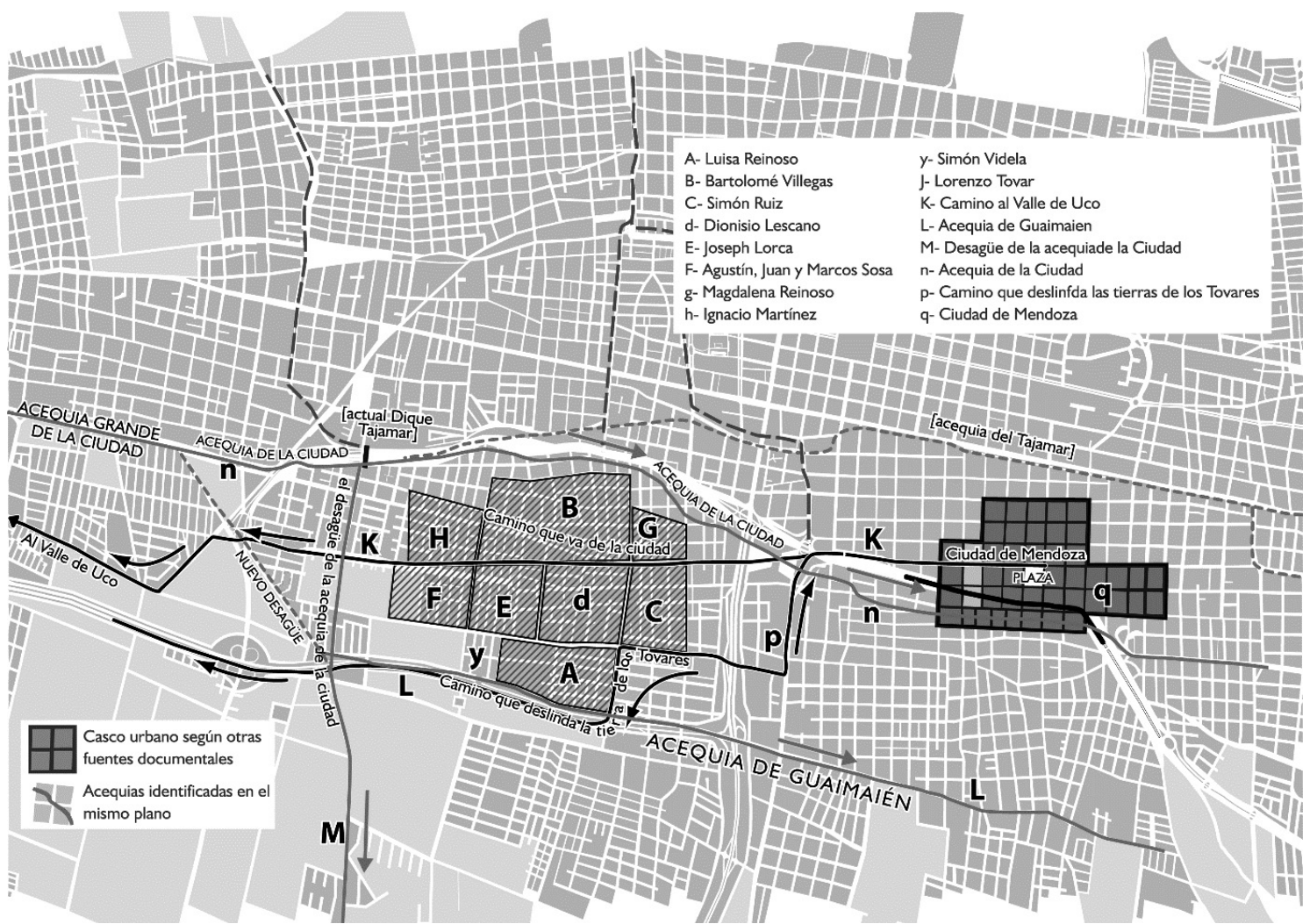

Fuente: PONTE, 2006, pág. 95.

\section{Del Goazap Mayu a la Acequia Grande de la Ciudad}

El actualmente conocido como Canal Zanjón en su porción comprendida entre la Toma en el Río Mendoza hasta la actual zona del Pilar en Dorrego [calles Zapala-Balcarce] [ver Figura 4]donde doblaba bruscamente en ángulo recto [desagüe antiguo] para dar origen al actual canal Confín Desagüe] fue conocido en tiempos prehispánicos, es decir, antes de la llegada del fundador Pedro del Castillo como Goazap-Mayu nombre que en lengua quechua significaría "río del Cacique Goazap".

De este nombre da cuenta específicamente un documento colonial ya mencionadocomo "Acta de los Caciques Comarcanos del 01/09/1574" en el Archivo Nacional de Chile. Según se desprende del documento, el cacique Goazap, había sido un cacique principal muy importante, en tanto toda la genealogía huarpe del asentamiento mendocino parece estar vinculada con él y lo señalan como fuente de legitimación dinástica.Al tiempo de la llegada de los españoles Goazap ya había muerto. Todos los caciques reconocen al este cacique como el dueño original de esta acequia que luego conoceremos como Canal Zanjón y de las tierras que esta acequia regaba, las que se habían transmitido sucesivamente a los otros caciques por medio de compra o trueque.[ver Figura 3].

El cacique Pelectay, según relatan los protagonistas en el Acta de 1574, le había comprado al cacique Goazap la propia acequia Goazap Mayu, y esta herencia la habría recibido el joven cacique Goaymaye de su padre, por un lado, mientras que de su madre también habría recibido unas tierras llamadas de Anancat, trocadas por su madre por una llama al cacique Coyo.

Como el problema secular de Mendoza no era tanto traer agua desde el río sino impedir 
precisamente que viniese demasiada; se fueron realizando en su trayecto desde el río, sucesivos "Tajamares" ya sea para parar la velocidad del agua, ya sea para derivarla a cursos menores, de manera de evitar los daños que producían las "avenidas" de agua en la ciudad.

Todo hace suponer que el Goazap Mayu-Zanjón discurre sobre una falla geológica que atraviesa la región con un sentido general norte sur, cubierta por relleno aluvional [ver Figura 3]. Por la información documental que se posee, podemos presumir que no constituía en el tiempo de la fundación y en la porción próxima a la ciudad, un curso de agua importante. Ello puede haberse debido a que el ramal Desagüe era el que derivaba el flujo principal hacia el este, y luego hacia el norte, hacia la zona conocida como "las ciénagas".

En los primeros tiempos de la vida de la ciudad colonial al Zanjón se lo conoció sucesivamente como: "Río de la Ciudad", "acequia principal de la ciudad" y, a veces, también simplemente como "Acequia Grande de la Ciudad", sobre todo en su tramo comprendido entre el Pilar y la boca del Río.

\section{El colapso del sistema de riego de la Acequia de la Ciudad por la irrupción del Zanjón}

En la obra "Desengaño y reparo de la guerra del Reino de Chile": publicada en la "Colección de Historiadores de Chile" por José Toribio Medina refiriéndose a Mendoza, hacia 1644, dice:

"Está situada Mendoza en sitio llano. Tendrá hasta cien casas anchurosas pero bajas como todas las de Chile, por respeto a los temblores de la tierra; espaciosas y derechas calles; una iglesia parroquial, dos monasterios, de frailes dominicos y de la Merced (...)"(DRAGHI LUCERO, 1938, pág. 453)

Jacinto Anzorena (ANZORENA, 1938, pág. 22) apunta un documento de 1715 , del que se infiere que las aguas de la Acequia Grande de la Ciudad [actual Canal Zanjón] habrían sido de- rivadas [hacia el norte] de su curso tradicional inconsultamente por un propietario [que presumimos de la zona de Dorrego]. Señala también este documento que se las habría dirigido hacia otro curso, probablemente al recientemente formado Zanjón, hecho que comenzó a provocar daños a la ciudad.

Precisamente esta imprudencia había dado la oportunidad de la llegada de algún aluvión o avance intempestivo y no deseado de las aguas de la Acequia Grande de la Ciudad, a mediados del siglo XVIII, según dan cuenta las Actas Capitulares de Mendoza. Este aluvión se habría sido llevado el relleno aluvional de esa falla geológica preexistente y habría dejado al dejado al descubierto un Zanjón. [verlímite interdepartamental en Figura 7]

Cuando a mediados del siglo XVIII se forma detrás de las Casas del Cabildo una formidable zanja, producto de una seguidilla de aluviones que asolan a la Ciudad de Mendoza por esos años. [ver Figura 7]Esta zanja o cauce aluvional cortó la suave pendiente que existía entre la Acequia de la Ciudad y la plaza mayor de Mendoza, impidiendo el riego desde esta acequia hacia la ciudad colonial. Los documentos dan cuenta de este colapso:

\section{"...ha impedido todos los caminos para el tráfico común, de suerte que es menester dar un gran ro- deo para entrar a comunicarse de un barrio a otro, estando cor- tado el paso en seis o siete boca- calles y algunas posesiones tan aisladas que no tienen por donde salir sus dueños y siendo como son regulares las avenidas que en esta ciudad se experimentan en tiempos de verano corriendo por las calles que atraviesan de oriente a poniente que desaguan en la dicha zanja..."(ACEVEDO, 1970, pág. 328)}

Efectivamente, a partir de entonces, coᄀmienza a hablarse del Zanjón que se habría formado detrás de las casas del Cabildo [ver límite interdepartamental en Figura 7]. Tal cual leemos 
Figura 6: Plano Mayorga Jurado. Tierras de María Miranda (1754) traspasado sobre la traza contemporánea de la ciudad. Plano levantado poco antes de la aparición del famoso Zanjón (1757)

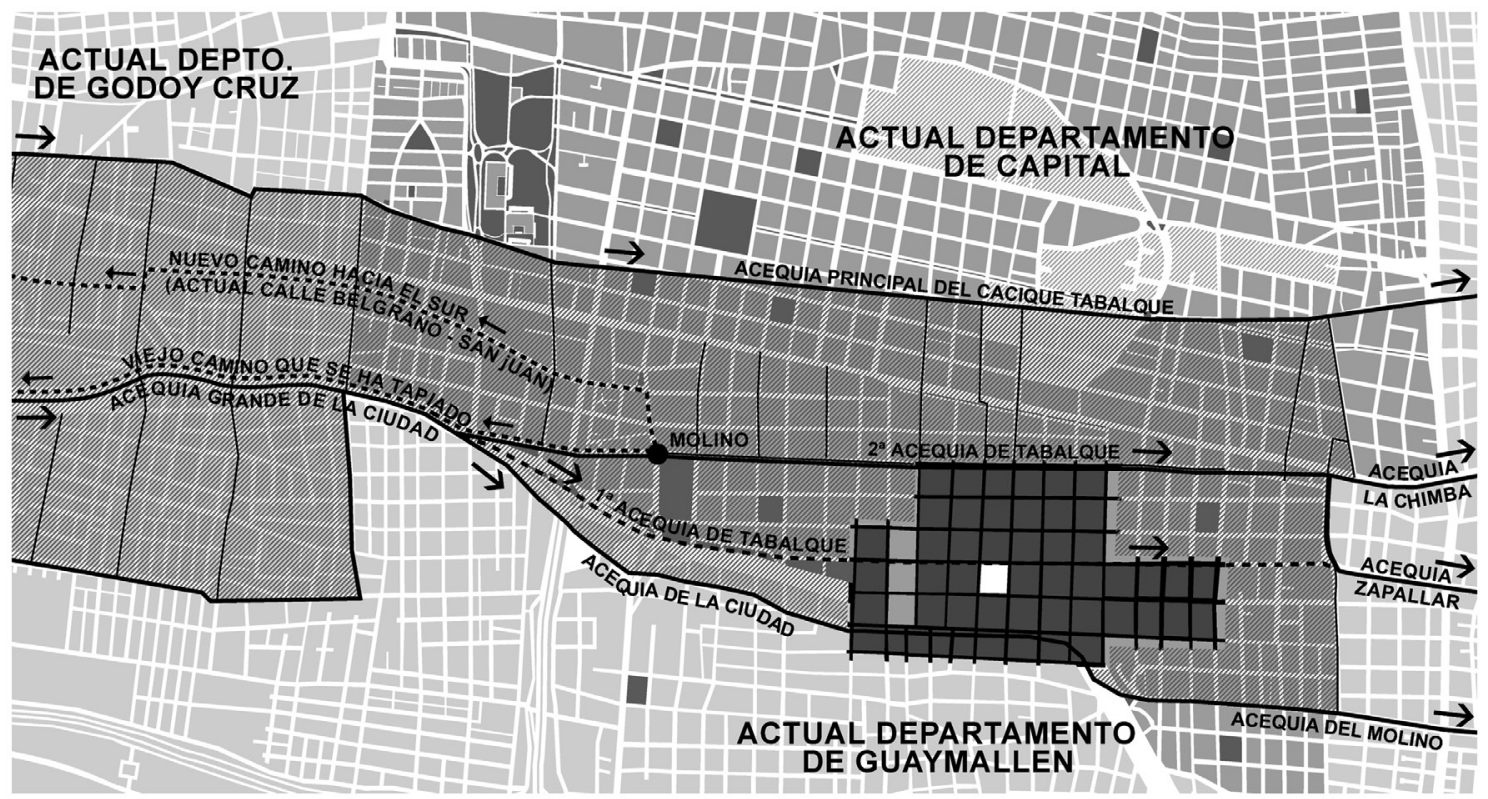

Fuente: Infografía de elaboración propia a partir de información documental.

en un Acta Capitular del 15 de no-viembre de 1755: “..las muchas aguas que for maron el gran zanjón, que tiene también cor-tada casi por la mitad a esta ciudad..."

Lo que apunta Anzorena, sumado al cambio de las condiciones pluviométricas que se produjeron en el siglo XVIII ${ }^{2}$, habrían sido causales de la profundización del cauce del Zanjón, la formaาción del barranco y el socavamiento de las caาsas del Cabildo, perjuicios de los que comenza $\neg$ ban a lamentarse los vecinos de Mendoza, a partir de mediados y hasta fin del siglo XVIII. Hubo una apelación al vecindario para rellenar la zanja que se había formado, pero la idea no prosperó.

Es el tiempo, entonces, de replantear el sistema de riego y prever que este sector de la Ciudad de Mendoza, tradicionalmente abastecido por la Acequia de la Ciudad, por calle Alberdi de San José, se abasteciera por la acequia de Tabalque, la que por entonces, ya circulaba por la actual calle Salta. [ver Figura 7] Hace pensar

2. Información suministrada por la Dra. María del Rosario PRIETO. Especialista en Climatología Histórica del IADIZA CCT. Mendoza. en esta posibilidad una observación del propio documento que estamos consultando:

"A este zanjón y barranca caen
los derrames de las hijuelas de
todas las casas, por estar en el
fin de las [¿hijuelas?] del nacien-
te [¿no debiera decir poniente?] y
su curso de ellas es del poniente
al naciente [lo cual es correcto]
porque todas las casas viven del
Tajamar..."(ACEVEDO, 1970, pág.
339)

La Acequia de la Ciudad, la que, por el inconveniente del Zanjón [actual Canal Zanjón] ya no provee de agua a la ciudad y a la que comienza a llamarse acequia Tovar por pasar por el Paso de Tovar [actual terminal de ómnibus de Mendoza] y a proveer de riego a la zona de San José-Pedro Molina, como había hecho desde siempre. La novedad es que ya no provee a la ciudad propiamente dicha, de allí que haya cambiado su nombre.

Dice el documento del 8 de mayo de 1761 elaborado por el Cabildo de Mendoza respecto del cambio de curso de la Acequia de la Ciudad, 


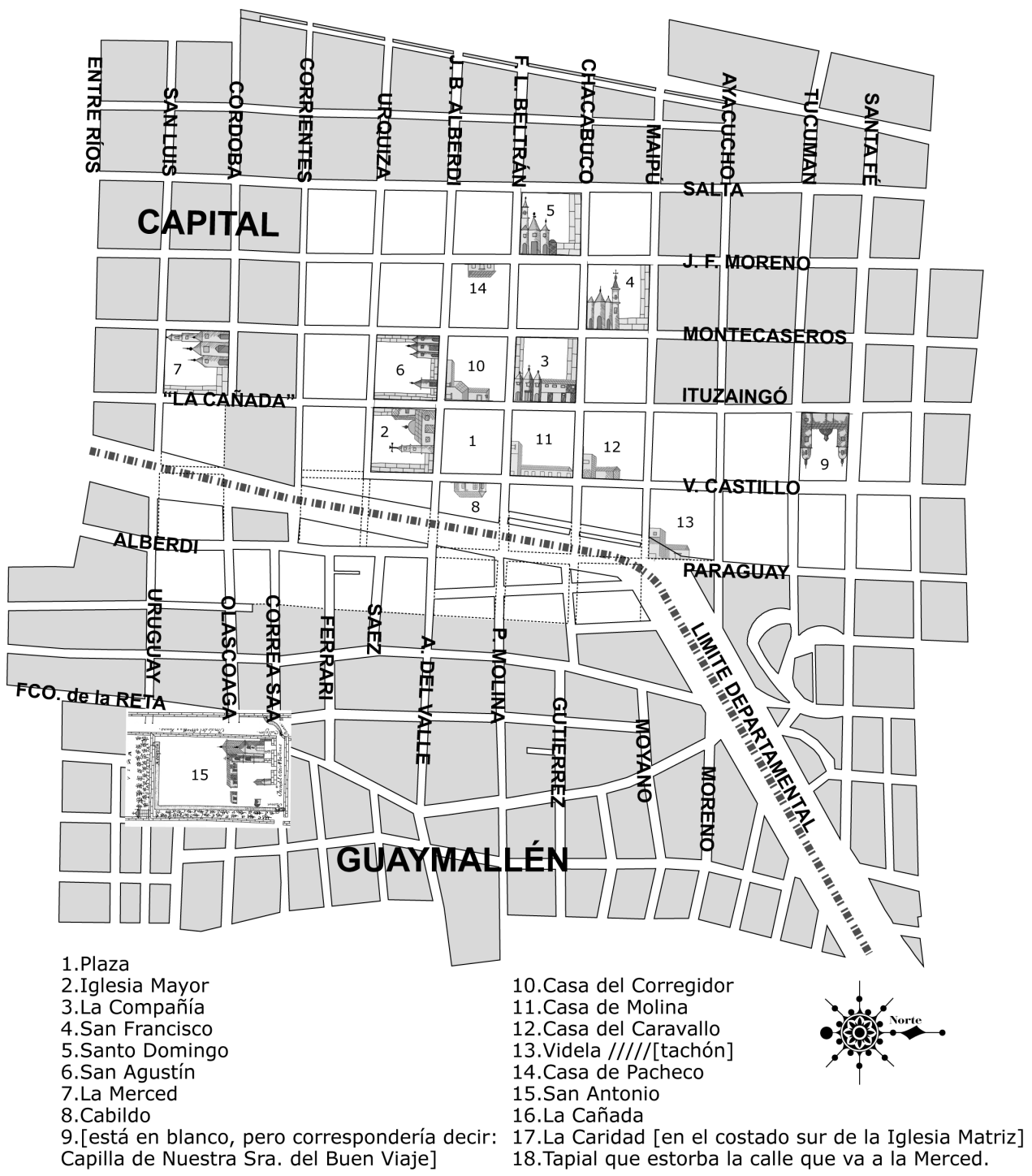

Fuente: Infografía de elaboración propia a partir de información documental.

a partir de su encuentro con el Zanjón [actual Canal Zanjón] en la zona de Pedro Molina, que:

\section{“... [a] dicha acequia de la ciudad} no se puede dar [aumentar] mayor cauce pues entra en las casas de la calle de $D^{n}$ Fernando Jurado [¿calle Alberdi?], en la acera fronteriza y una creciente las arruinará todas; antes de la barranca [¿actual Canal Zanjón?] forma acequia por ella [¿atraviesa la barranca? ¿Es decir al Zanjón?] cayendo detrás del molino de los Reverendos Padres de la Compañía [actuales calle Paraguay y calle de los Pescadores] y así por no aumentar a dicho Zanjón por su barranca esta agua y por remediar con ellas a los que se quedaron en seco perdiendo sus tomas y están al naciente [al este], se le dio otro curso"[el destacado es nuestro]. (ANZORENA, pág. 339)

Probablemente, el cambio de curso al que se refiere el documento es que la Acequia de la Ciudad, en que vez de seguir hacia el norte, atravesando el cauce del recién formado Zanjón [actual Cacique Guaymallén], se la hizo girar 
hacia el este, hacia el actual distrito de Pedro Molina y dirigirla hacia la zona de las ciénagas en el distrito de La Lagunita.[ver Figura 4]

Vista la situación de colapso provocada por la aparición del Zanjón [actual Canal Zanjón] se propone como "más conveniente abrir más cauce a las tres acequias que corren por las barrancas"[¿del Zanjón?]. Aunque no se aclara a cuales acequias se está refiriendo, podemos presuponer que habla de las acequias del Tajamar vieja [con toma en calle Zarate-Morón, aquella que conocimos en tiempos fundacionales como la acequia de Tabal y luego conocida como acequia de Pardo o de Pouget], la acequia de Tajamar nueva [con toma a la altura del Club Antonio Tomba] y a la Acequia del Molino de la Cía. de Jesús que corría por la actual calle Ramírez de Capital todas ellas con tomas en la margen oeste del mismo Zanjón [Canal Zanjón].[ver Figura 4]

Durante los primeros tiempos se pensó que ese Zajón podía ser rellenado, empresa que desbordaba las posibilidades tecnológicas de los mendocinos de entonces. El Zanjón apareció para quedarse en la vida de los mendocinos. Desde entonces, ya directamente se pasó a denominar simplemente "el zanjón" de la ciudad, sin otro nombre propio adicional.

El obispo Ambrosio José de Ochoa, cura y vicario de Mendoza produjo en 1787, un informe remitido al Cabildo de la Ciudad, donde previene sobre el constante peligro de las inundaciones, las cuales día a día profundizaban el Canal Zanjón "que ha destruido bastantes edificios y cuyas barrancas están demasiado inmediatas a la iglesia Parroquial y Casas del cabildo." (MARTÍNEZ, 1961, pág. 370)Asimismo, el religioso advierte el inminente peligro de derrumbe de las paredes laterales de las acequias, que las taponan impidiendo el normal curso del agua hacia la periferia urbana del sistema de regadío.

El mencionado Zanjón corre de sur a norte, pero ya eran también importantes las cañadas que traían el agua de la precordillera, es decir, de oeste a este, una de las cuales corría "al sur de la iglesia, de oriente a poniente, y que se ha in- ternado hasta más de la media cuadra de la calle real, dejando pendiente partes de los cimientos de la muralla."(MARTíNEZ, 1961, pág. 370)

Por su parte, el Marqués Rafael de Sobre Monte (1789) funcionario español que llegaría a ser Virrey del Río de la Plata, visitó Mendoza en 1789 , siendo gobernador-intendente de Córdoba del Tucumán. [ver Figura 4]Dirá de la ciudad:

“...Esta regada por un río que desciende de la cordillera de Chile, el que provee una acequia de ocho leguas de distancia, de la cual, por lo deleznable del terreno se forma un Zanjón en el centro del pueblo, que en las crecientes del río, unidas con las avenidas de las sierras inmediatas hicieron un terrible cauce, de que una y otra banda padecía derrumbes; con que han perdido considerable número de casas y porciones de viñas; (...) por lo cual se resolvieron en 1788 al gasto de una obra en el río, contratada con el arquitecto José Ponte [correspondería decir Comte] (...) para recibir las vertientes de la sierra y dar riego a una porción de tierra de temporalidades [se trataba del canal Jarillal o Jarillar] (...) ha evitado aquel repartimiento de cada año entre el vecindario y las calamidades que padecían en las ruinas de sus casas, quedando asegurada la iglesia Mayor, las casas capitulares y la carnicería que ya amenazaba una próxima ruina..." (DRAGHI LUCERO, 1938, pág. 538)

\section{Descripción de la ciudad al comenzar el siglo XIX}

Eusebio Videla, diputado de comercio por Mendoza y a quien Arturo Roig considera el primer escritor local, publica en el "TelégrafoMercantil" en 1801, una semblanza de Mendoza; la misma constituye también el primer artículo periodístico sobre la ciudad, que se editará en el país: 
Figura 8. Detalle del plano de 1822 donde se ve el Zanjón que atraviesa la manzana del Cabildo frente a la Plaza Principal.

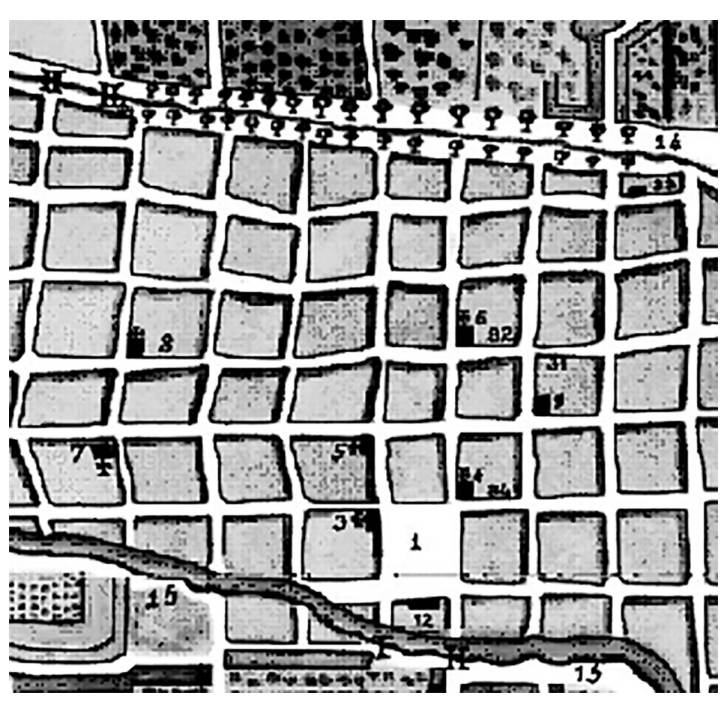

Fuente: (PONTE, 2008, pág. 121)

"...con todos estos edificios y casas particulares hay la comodidad y recreo de jardines, huertas de árboles y legumbres, cuyo apreciable cultivo les proporciona la abundante provisión de aguas de regadío, que extraen sus vecinos del caudaloso río de su nombre, $y$ por medio de acequias la hacen correr, no sólo por todos los sitios de la ciudad sino también por todo el largo espacio de más de 30 leguas que comprenden en área sus dilatadas fincas o haciendas en que hay edificios tan buenos como en la misma ciudad." (VIDELA Y VALENZUELA, 1938, pág. 185/190)

\section{La degradación del Zanjón a fines del siglo XIX}

El canal Zanjón, aquel que el chileno Vicuña Mackenna describiera en 1854 como "tan cerca lo agreste de lo civilizado" lleno de rosales silvestres, y que constituía el borde este de la ciudad vieja, es, hacia 1887 , el sitio donde se arrojan las basuras. La prensa denuncia que el sitio es «un foco de inmundicias que exhalan un olor insoportable» [EI F.C.,9/8/1887]
Por otro lado, es frecuente leer en la prensa quejas por los rebalses de las aguas del canal Zanjón, sobre todo en época de deshielos.

"Cloaca. El Zanjón como es notorio es el desagüe obligado de todas las calles del municipio, donde van a parar las basuras que se encuentran en la vía pública. (...) y diariamente al canal Zanjón los desperdicios de la matanza de animales. El que se atreva a pasar por el puente de Matadero [actual cruce de Beltrán - Pedro Molina] podrá ver en estos días su parte Norte convertida en depósito de tripas, bofes, mondongos, y cuanto detalle puede producir el arte del matarife. Pedimos al Sr. Intendente la cremación de todos estos desperdicios en vez de permitir los arrojen al Zanjón..." [L.A.,13/5/1899]

Según habíamos señalado, el problema secular del Canal Zanjón no fue tanto el traer agua hacia la ciudad sino el evitar que ésta viniera en exceso y pudiera entrar en la ciudad. Por ello, en su curso de casi $40 \mathrm{~km}$. se construyeron diques derivadores tales como el Dique Gil, el Dique Carrodilla y el Dique Sobre Monte.

La misión de estos diques era derivar las aguas del Zanjón hacia ambas márgenes del mismo y distribuirlas en un amplio radio de riego.[ver Figura 4]El primero aguas abajo del Zanjón es el Dique Gil, ubicado a unos 6 km. aguas abajo del actual Dique Cipoletti. Tiene 12,50 m. de largo y una sola toma, en la margen derecha, de donde arranca el canal matriz Gil, que corre paralelo al Zanjón pero a una altura más superficial, no tan profundo como el cauce del Zanjón.

El segundo, y el más importante de toda la red del Zanjón es el Dique Carrodilla del cual, sobre la margen derecha arranca el canal matriz Sobre Monte y de la izquierda el canal Jarillar (o Jarillal). El tercer dique es el del Pilar que sirve para derivar el agua del Canal Confín Desagüe. Hacia comienzos del siglo XIX salía también de esa toma la acequia del Molino de Pouget 
Figura 9. El Zanjón en su porción que atraviesa la ciudad. Detalle del plano de la Ciudad de 1872/3

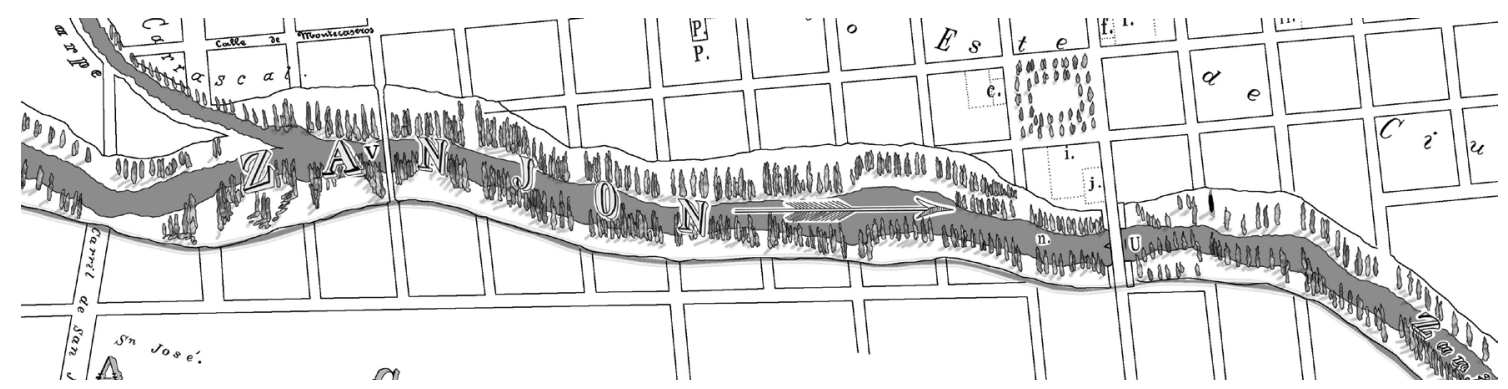

Fuente: Infografía de elaboración propia a partir de información documental

[actualmente desaparecida] y el dique funcionaba con compuertas automáticas las cuales se volcaban o subían de acuerdo a la altura del agua del Canal Zanjón, con sus respectivos desarenadores.

Hacia 1910, distribuían el riego de esta zona 20 canales principales que repartían, a su vez, las aguas del río entre 77 hijuelas y ramos [canales secundarios y terciarios] de los cuales salían las acequias particulares que regaban 6.000 propiedades que componían, para la época, el núcleo agrícola. Tal cantidad demostraría la subdivisión de la tierra agrícola en la futura Área Metropolitana de Mendoza.

\section{El Canal Zanjón y la fuerza hidráulica}

Un proto-empresario local, el Ing. Fader ensaya la iluminación por medio del gas acetileno en una velada del Teatro Municipal. También el mismo empresario ha propuesto usar el canal Zanjón como fuerza motriz [L.A.,22/5/1897] idea de que recurrentemente aparece en estas décadas.

Por otro lado, hacia 1897 se otorga una concesión pública a Guillermo Kevel y Cía. para instalar turbinas en el canal Zanjón (actual Cacique Guaymallén) y poder organizar así tranvías eléctricos. [L.A.,25/11/1897]

La prensa da cuenta de una iniciativa legislativa para usar la fuerza motriz de los canales para mover turbinas que permitan utilizar la energía eléctrica en los tranvías y en las bodegas vitivinícolas. [L.A.,2/6/1898]
Según el ingeniero Galileo Vitali, en su artículo sobre la evolución de la irrigación en Mendoza [1938] agregarespecto del Canal Zanjón que, a fines de 1914, bajo el gobierno de Francisco Álvarez, más conocido como "Dn Pancho Hambre" se canalizó e/ Zanjón como manera de paliar la gran desocupación que habría en la provincia por efecto de la primera guerra mundial.

Las observaciones del Ingeniero Anzorena, señaladas ut supra (ANZORENA, 15/9/1933) hasta ahora aparentemente sólo de carácter histórico, son muy pertinentes. En materia de aguas interesa conocer el origen natural o cultural del curso de agua.

“...nuestra legislación establece
diferencias, en cuanto a la propie-
dad de los terrenos ribereños[el
destacado es nuestro] entre los
ríos y los canales. En el primer
caso se considera "de propiedad
fiscal toda la tierra cubierta por las
aguas, en sus máximas crecidas;
en el segundo, los terrenos ocupa-
dospor canales y una parte de sus
márgenes están sometidos a las
disposiciones sobre servidumbre,
que sólo afecta al propietario del
terreno mientras el canal esté en
servicio".(ANZORENA, 15/9/1933,
pág. nota 3 folio 3)

De que el Gobierno adoptara una tesis (origen natural) u otra tesis (origen artificial), dependía, sin duda, el qué hacer en las márgenes del mismo en la porción que acompaña al conglomerado urbano del Gran Mendoza. Ello se señala 
Figura 10. La situación hídrica hacia fines del siglo XVIII. Infografía de elaboración propia a partir de información documental.

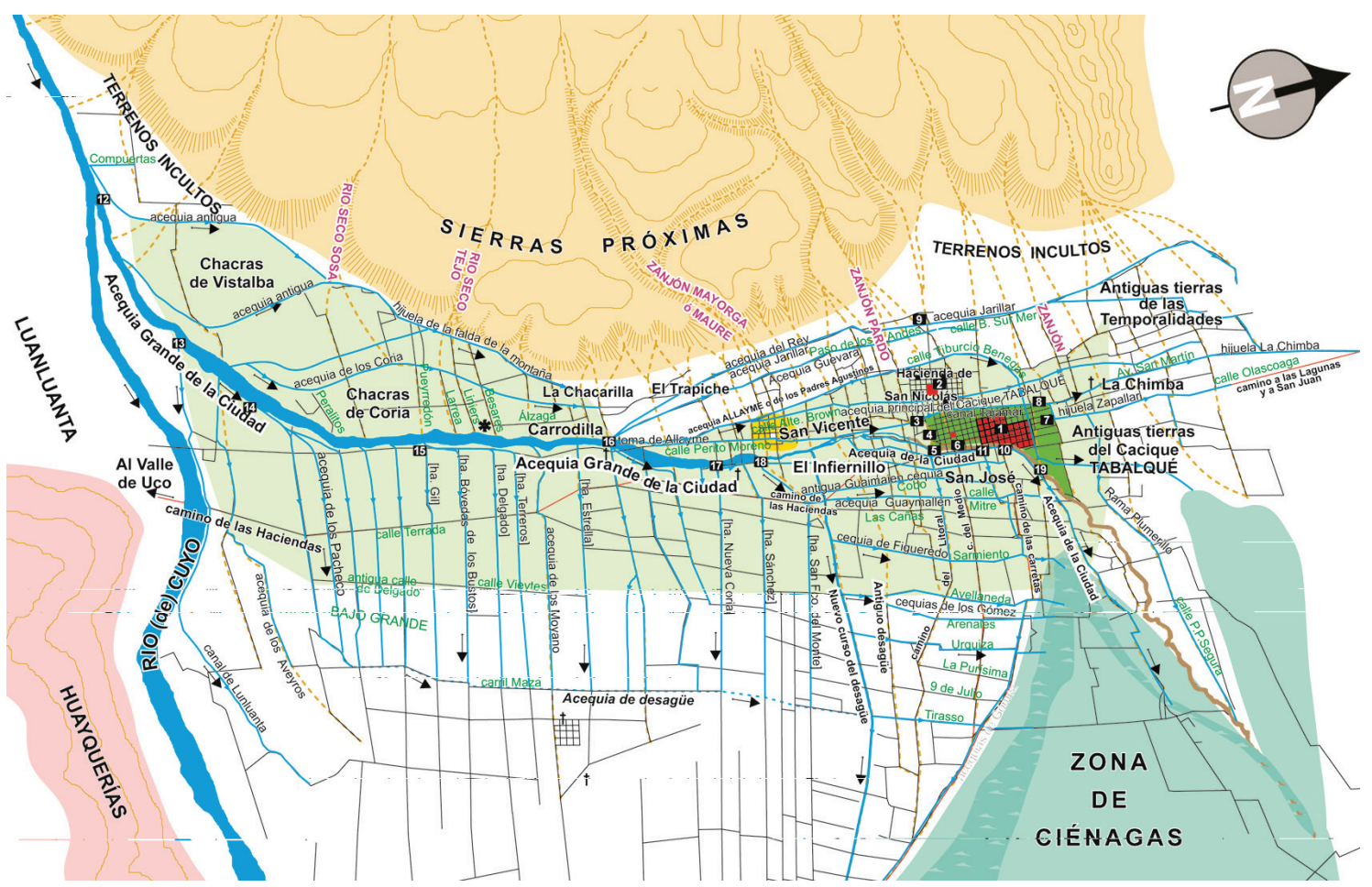

Fuente: Infografía de elaboración propia a partir de información documental. (PONTE, 2006, pág. 134).

en el Informe al entonces Ministro de Industrias y Obras Públicas de la Provincia:

Si observamos el lecho del Río frente a la toma vieja, nos encontramos con que está en crecimiento desde muchos años atrás por extenderse hasta más arriba su cono de deyección, circunstancia que forzosamente determina la divagación de las aguas con tendencia siempre a venirse hacia el Norte por falta de barrancas (...) Las obras construidas en donde el Zanjón se desprende del Río han tendido más bien a impedir un exceso de agua del canal que a derivarla por éste"(ANZORENA, 15/9/1933)

El mismo Anzorena (1915) fue el impulsor y gestor de la construcción de la Avenida Costanera-Avenida del Este que bordearía, tal como lo hace en la actualidad, todo el Canal Zanjón ya culturizado, a lo largo de todo su límite este, en la porción correspondiente al Municipio de Capital.Tenemos entendido que, finalmente, el Gobierno no adoptó una postura clara al respecto y que, por tramos, consideró fiscal la propiedad mientras que en otros procedió a expropiar para construir dos vías costaneras las que en la actualidad vinculan con los accesos Norte y Sur a la ciudad. (COROMINAS SEGURA, 1942)

El informe Anzorena vaticinaba en 1933: "La sistematización del Zanjón, hará posible la rehabilitación de muchos terrenos adyacentes que, si fueran propiedad del Estado, nos servirán para el establecimiento de calles laterales a uno y a otro lado del cauce rectificado..." (ANZORENA, 15/9/1933, pág. folio 3)

A partir de 1935, con fondos nacionales, se impermeabilizaron los cauces aluvionales tales como el Zanjón Frías, o el Zanjón de los Ciruelos o el Zanjón Maure y el propio Canal Zanjón como forma de facilitar los desagües aluvionales luego de la terrible experiencia vivida el año anterior con el famoso aluvión de Cacheuta de 1934. 
Figura 11. Tramo donde se ve el Zanjón no canalizado antes de su ingreso en la ciudad de Mendoza. Fotografía del autor.

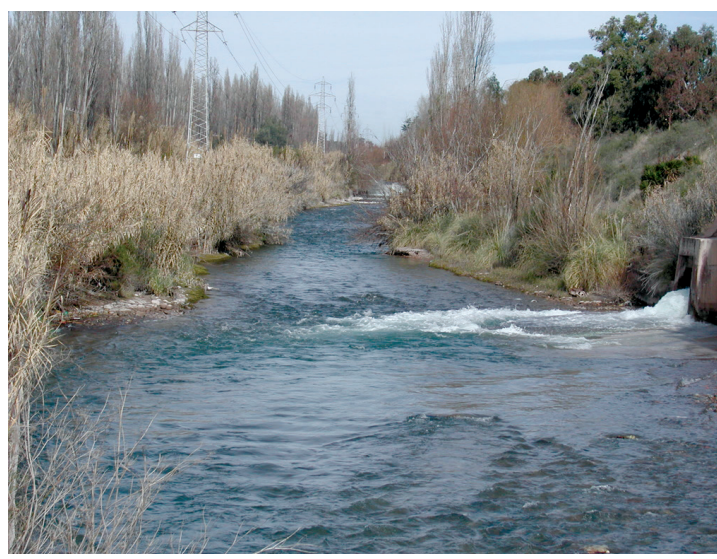

Fuente: elaboración propia

\section{Del Canal Zanjón al Canal Zanjón Cacique Guaymallén}

Los diarios mendocinos La Palabra del 20/10/1950 y Los Andes del 22/10/1950 dan la noticia que el Departamento General de Irrigación, a solicitud del Honorable Concejo Deliberante y del Ejecutivo de la Municipalidad de Guaymallén denominará, en lo sucesivo, al Canal Zanjón con el nombre de Canal Zanjón Cacique Guaymallén. Ninguna de las dos crónicas da cuenta de los argumentos esgrimidos por los ediles departamentales. Puede que los promotores o difusores del nombre de cacique Guaymallén no hayan conocido el documento tan revelador de los caciques comarcanos, publicado por primera vez en 1954 por parte del historiador chileno Juan Luis Espejo.

Las dos avenidas que actualmente bordean ambas márgenes del Canal Zanjón, en el tramo correspondiente a la porción más urbanizada del Área Metropolitana de Mendoza, se las conoce popularmente como "Avenida Costanera". El lenguaje, que de todo lo importante da cuenta, nos revela que no es ingenuo que en una ciudad que no tiene costa de río ni de mar se hable de una avenida Costanera._iSí!jLa costanera del Zanjón!

Mendoza es, desde el siglo XVI hasta nuestros días, un ejemplo elocuente de la importancia histórica del tema hídrico en el desarrollo de su
Figura 12. Tramo donde se ve el Zanjón canalizado durante su paso por la ciudad de Mendoza.

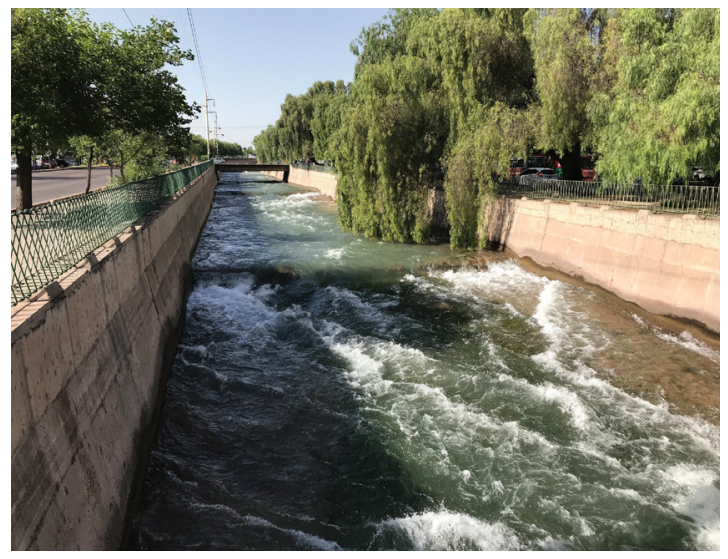

Fuente: fotografía del autor.

actual Área Metropolitana a punto tal que existe otra historia de la ciudad más allá de sus edificios y terremotos. Así, en nuestro caso, los hitos históricos del agua han sido la aparición puntual de planos o mapas que refieren a pleitos de vecinos por usos indebidos del agua, temas de riego, de usos de molinos, de acequias, de zanjones y canales, de inundaciones, etc.

El gran historiador francés Fernand Braudel, padre de la llamada historia de "la larga duración", sostenía que, cuando a la historia se le saca lo episódico, las guerras y batallas, la trayectoria de sus gobernantes, etc., lo que queda...es la historia.

En efecto, los estudios de larga duración tienden a explicar la conformación del "modelo" de asentamiento urbano y territorial a través de un largo período de tiempo. Se trata de una nueva manera de estudiar les relaciones entre las sociedades y los territorios, situando sus relaciones en los periodos largos que ponen en valor las evoluciones, las rupturas y les continuidades de los diferentes modos de ocupación del espacio.

En nuestro caso, la historia de la larga duración la protagonizan las acequias, portadoras del agua y, por ende, de la vida en una región semidesértica y de oasis como Mendoza, como aquellas otras donde nacieron las primeras civilizaciones de la humanidad. 


\section{Bibliografía:}

ACEVEDO, E. O. (1970). Sobre el problema del riego en Mendoza. Contribución documental. Revista de Estudios Históricos de Mendoza, $2^{\mathrm{a}}$ época, Tomo 1, 1, 2ª época(6).

ANZORENA, J. (15/9/1933). Informe al Sr. Ministro de Industrias y Obras Públicas de la Provincia, Ing. E. López Frugoni. Ministerio de Obras Públicas de la Provincia de Mendoza. Mendoza: material inédito.

ANZORENA, J. (1938). La toma de los españoles. El Río, el Zanjón y la Ciudad. Actas Congreso Historia de Cuyo. Mendoza: Best Impresores.

COROMINAS SEGURA, R. (1942). Provincia de Mendoza. Labor de Gobierno-Período 1938-1941. Mendoza: Imprenta Oficial.

DRAGHI LUCERO, J. (1938). Cancionero Popular Cuyano. Mendoza: Best Impresores.

DRAGHI LUCERO, J. (1938). Crónicas de Cuyo. En C. P. Cuyano (Ed.), Anales del $1^{\circ}$ Congreso de Historia de Cuyo.VIII. Mendoza: Best Impresores.

JUNTA DE ESTUdIOS HISTÓRICOS DE MENDOZA. (1961). Actas Capitulares de Mendoza (Vol. II). Buenos Aires, Argentina: Imprenta López.

MARTíNEZ, P. S. (1961). Historia Económica de Mendoza durante el Virreinato. (1776-1810). (I. G. Oviedo, Ed.) Madrid.

MEDINA, J. T. (1898). Colección de documentos inéditos para la Historia de Chile desde el Viaje de Magallanes hasta la batalla de Maipú (1518-1818) (Vol. XV). Santiago de Chile: Imprenta Elzeviriana.

PONTE, J. R. (2006). DE LOS CACIQUES DEL AGUA A LA MENDOZA DE LAS ACEQUIAS. Cinco siglos de historia de acequias, zanjones y molinos. Mendoza, Mendoza, Argentina: Ediciones "Ciudad y Territorio" INCIHUSA-CONICET.

PONTE, J. R. (2008). MENDOZA, AQUELLA CIUDAD DE BARRO. Ilustrado. Historia de una ciudad andina, desde el siglo XVI hasta nuestros días. Buenos Aires: Imprenta Unión.

PROVINCIA DE MENDOZA. (1910). Censo General de la Pcia. de Mendoza. Levantado el 18/8/1909. Buenos Aires: Cía. Sudamericana de Billetes de Banco.

VIDELA Y VALENZUELA, E. (1938). Descripción de la Ciudad de Mendoza (al comenzar el siglo XIX). En Anales del Primer Congreso de Historia de Cuyo (El Telégrafo-Mercantil. 1801 ed., Vol. VII). Mendoza.

Fuentes:

Plano 1561 [Archivo General de Indias], infografía propia de 1561-66, plano 1754 [Archivo Nacional de Chile], plano 1758 [A.N.Ch.], plano 1761 [A.N.Ch.], plano 1764 [A.N.Ch.], plano 1822 [A.N.R.J. Archivo Nacional de Río de Janeiro], plano de Ciudad de 1872/73 y territorial de esos mismos años, fueron las fuentes cartográficas y topográficas que sirvieron de base para construir nuestras propias infografías.

Abreviaturas: Diario "Los Andes", Mendoza: [L.A.] 
